\title{
Fibroblast Growth Factor-2 in Remodeling of the Developing Basement Membrane Zone in the Trachea of Infant Rhesus Monkeys Sensitized and Challenged with Allergen
}

\author{
Michael J. Evans, Laura S. Van Winkle, Michelle V. Fanucchi, Gregory L. Baker, \\ April E. Murphy, Susan J. Nishio, Edward S. Schelegle, Laurel J. Gershwin, \\ Philip L. Sannes, and Charles G. Plopper
}

Department of Anatomy, Physiology, and Cell Biology, Center for Comparative Respiratory Biology and Medicine, School of Veterinary Medicine, University of California, Davis, California

SUMMARY: Remodeling of the epithelial basement membrane zone (BMZ) involves increased deposition of collagen, resulting in thickening of the BMZ. The current study focuses on fibroblast growth factor-2 (FGF-2) in the tracheal BMZ in house dust mite allergen (HDMA)-sensitized infant rhesus monkeys, challenged with HDMA at a time when the BMZ is undergoing active postnatal development. To detect structural changes in the BMZ, we measured collagens I, III, and V. To detect changes in the function of the BMZ, we measured immunoreactivity of the heparan sulfate proteoglycan, perlecan, and FGF-2. We found significant thickening of the tracheal BMZ $(p<0.05)$ with each of these parameters. We also found that all HDMA tracheal samples expressed thin focal areas of the BMZ associated with leukocyte trafficking. These areas were depleted of perlecan and FGF-2; however, increased FGF-2 immunoreactivity was present in the adjacent basal cells. We conclude that basal cells and FGF-2 are involved with significant remodeling of the BMZ in the developing trachea of infant rhesus monkeys exposed to HDMA. (Lab Invest 2002, 82:1747-1754).

$T$

he basement membrane zone (BMZ) is the central structure of the epithelial-mesenchymal trophic unit. The epithelial-mesenchymal trophic unit consists of opposing layers of epithelial and mesenchymal cells separated by the BMZ (Evans et al, 1993, 1999; Holgate et al, 2000). The BMZ has a number of functions in the epithelial-mesenchymal trophic unit. It is specialized for attachment of epithelium with the extracellular matrix. It also serves as a barrier; binds specific growth factors, hormones, and ions; is involved with electrical charge and cell-cell communication (Adachi and Hayashi, 1997; Crouch et al, 1997; Sannes and Wang, 1997). Remodeling of the epithelial BMZ involves increased deposition of subepithelial collagen resulting in thickening of the BMZ (Bousquet et al, 2000; Brewster et al, 1990; Redington, 2000). The lamina reticularis is the region of the BMZ in human large airways that accumulates collagen and

\section{DOI: 10.1097/01.LAB.0000043911.94235.F3}

Received October 16, 2002.

This work was supported by NIH Grants ES00628, ES04311, ES06700, ES05707, HL 44497, and RR000169 and American Lung Association and EPA Grant R827442-01-0.

Address reprint requests to: Dr. Michael J. Evans, Department of Anatomy, Physiology, and Cell Biology, Center for Comparative Respiratory Biology and Medicine, School of Veterinary Medicine, University of California, Davis, California 95616.E-mail:mevans@ucdavis.edu leads to the subepithelial fibrosis associated with asthma. Thickening of the BMZ is thought to protect against airway narrowing and air trapping (Milanese et al, 2001). It is not known how remodeling affects the various functions of the $B M Z$.

The BMZ appears as three component layers when viewed with transmission electron microscopy: the lamina lucida, the lamina densa, and the lamina reticularis. Together they make up the basal lamina. The lamina reticularis is not apparent in all tissues; however, it is well developed under multilayered epithelium. It is especially pronounced under the respiratory epithelium of large conducting airways, where it may be several microns thick (Merker, 1994). The lamina reticularis is made up of numerous collagen fibrils. Immunohistochemical studies have shown that the collagen fibrils consist of Types I, III, V, VI, and VII collagen (Merker, 1994). The collagen fibrils are arranged as a mat of large fibers oriented along the longitudinal axis of the airway when viewed with scanning electron microscopy. Smaller fibers are cross-linked with the larger fibers to complete this structure (Evans et al, 2000b). The BMZ also has numerous pores (Evans et al, 2000b; Howat et al, 2001). Heparan sulfate proteoglycans (perlecan), chondroitin sulfate proteoglycans (bamacan), and growth factors bound to the proteoglycans are within and around the collagen fibrils (Roberts et al, 1997; Sannes et al, 1992, 1993). 

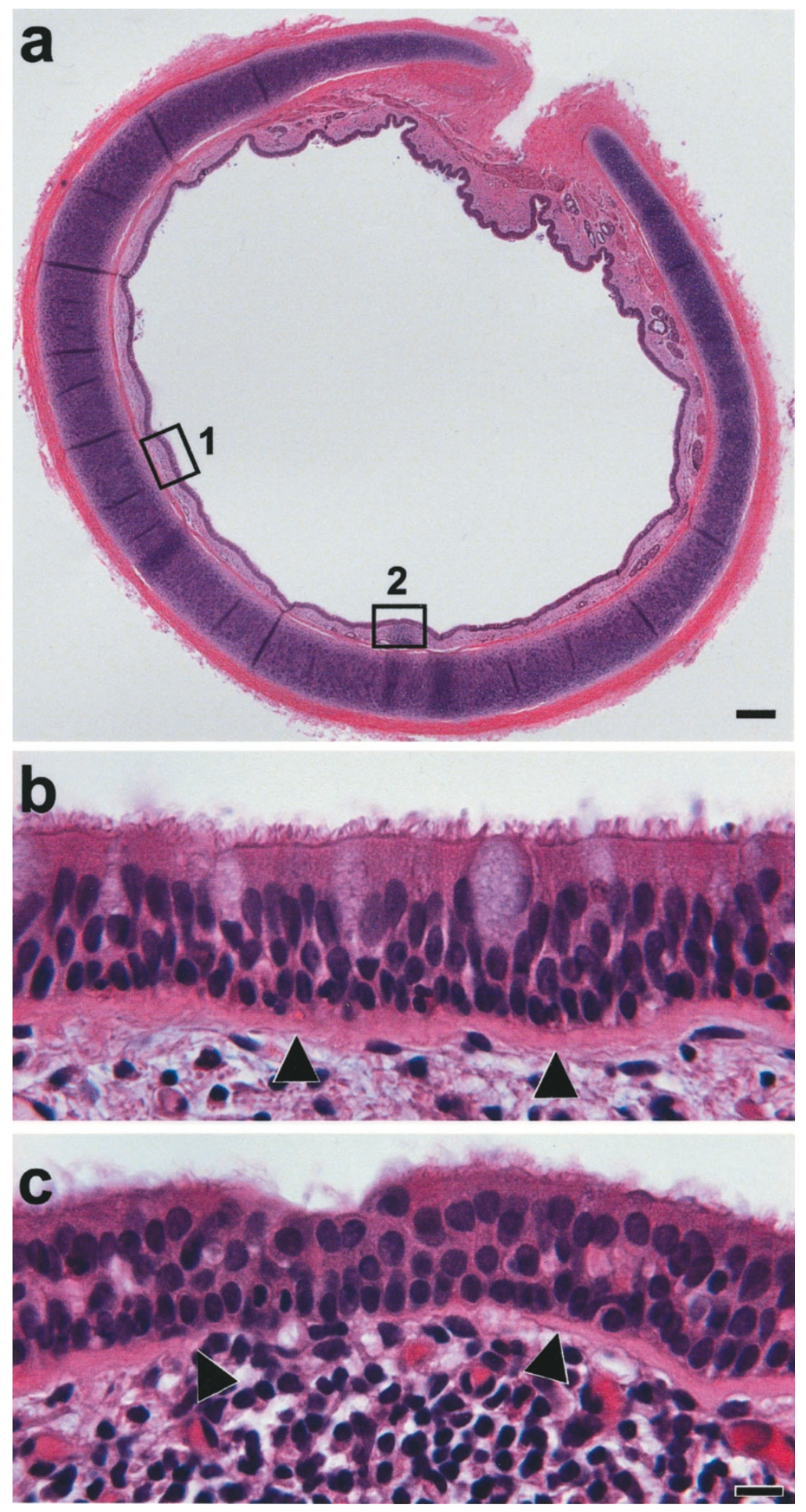

Figure 1.

a, Hematoxylin and eosin image of a tracheal ring from monkey treated with HDMA. Areas (1) and (2) are shown at a higher magnification in Figures 1 , b and c, respectively. Bar $=230 \mu \mathrm{m}$. b, A normal-appearing portion of the tracheal BMZ (arrowheads) near the area of leukocyte trafficking shown in Figure 1c. c, In the area of leukocyte trafficking (arrowheads), the BMZ appears to be degraded. The magnification of $\mathrm{b}$ and $\mathrm{c}$ is the same. Bar $=10 \mu \mathrm{m}$.

Binding and storage of growth factors is an important function of the BMZ. Fibroblast growth factor-2 (FGF-2) is the main growth factor stored in the BMZ (Folkman et al, 1988; Sannes and Wang, 1997). The FGF-2 is stored in the BMZ of airway and alveolar epithelium, endothelium, and smooth muscle cells in the lungs of developing and adult rats (Powell et al, 1998; Sannes et al, 1992). Presumably it is stored in the $\mathrm{BMZ}$ for rapid cellular responses to changes in local environmental conditions in the epithelialmesenchymal trophic unit (Bikfalvi et al, 1997; lozzo, 1998; Nugent and lozzo, 2000; Taipale and Keski-Oja, 

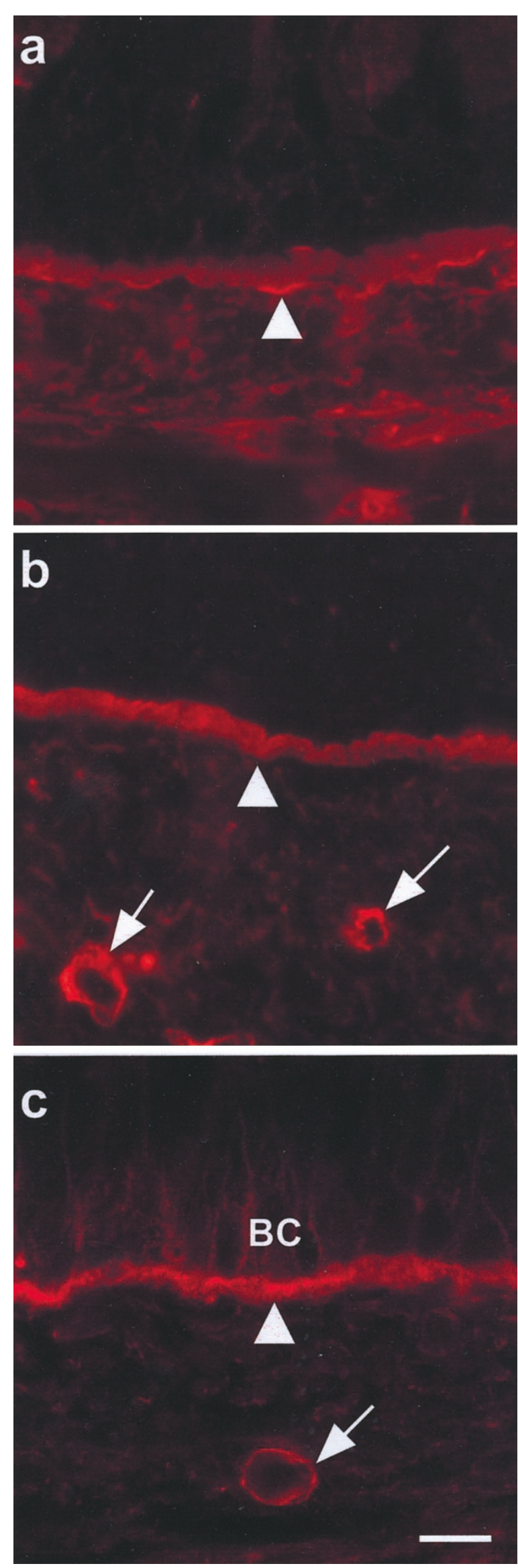

1997). The FGF-2 is stored in the BMZ through binding with perlecan, a heparan sulfate proteoglycan that is an integral constituent of the BMZ. It can be released from perlecan in response to various conditions and become an important cytokine within the local microenvironment of the epithelial-mesenchymal trophic unit (Bikfalvi et al, 1997; Dowd et al, 1999). Thus, perlecan functions in part as a regulator of FGF-2 function.

We recently defined development of the $B M Z$ in the trachea of infant rhesus monkeys at 1 to 6 months of age (Evans et al, 2002). To document structural changes in the developing BMZ, we measured immunoreactivity of collagen types I, III, and V. To detect more dynamic, functional components of the BMZ, we evaluated the distribution of perlecan, FGF-2, and fibroblast growth factor receptor-1 (FGFR-1). Onemonth-old monkeys had a mean collagen $\mathrm{BMZ}$ width of $1.5 \pm 0.7 \mu \mathrm{m}$. This increased to $4.0 \pm 0.9 \mu \mathrm{m}$ in 6 -month-old monkeys. Perlecan was localized in the $\mathrm{BMZ}$ of the epithelium at all ages. The FGFR-1 immunoreactivity was expressed by basal cells and cilia and weakly in the nuclei of columnar cells at all time points. The FGF-2 was strongly expressed in basal cells at 1 to 3 months but not in the BMZ. However, the opposite distribution of FGF-2 was observed at 6 months. It was now expressed strongly throughout the $\mathrm{BMZ}$ and weakly in basal cells. The BMZ width of $4.0 \pm 0.9 \mu \mathrm{m}$ is similar to the width measured in adult rhesus monkeys (4.2-6.3 $\mu \mathrm{m}$ ) (Evans et al, 2000a). We concluded that (1) development of the $\mathrm{BMZ}$ is a postnatal event in the rhesus monkey and (2) FGF-2 expression by basal cells is associated with development of the $\mathrm{BMZ}$.

In a previous study of adult rhesus monkeys sensitized with house dust mite allergen and exposed to allergen, we found significant remodeling of the $B M Z$ (Schelegle et al, 2001). The purpose of the present study was to determine if a similar allergen treatment affected development of the BMZ in infant rhesus monkeys. Here we focus on FGF-2 in the tracheal $\mathrm{BMZ}$ in house dust mite allergen (HDMA)-sensitized infant rhesus monkeys challenged with HDMA during the first postnatal 6 months. From our previous study, we know this is a time when the BMZ is undergoing active postnatal development (Evans et al, 2002). To detect structural changes in BMZ development, we measured collagens I, III, and V. To detect functional changes in the BMZ, we measured the distribution of perlecan and FGF-2.

\section{Figure 2.}

a to $\mathrm{c}$, From the filtered-air group. The magnification is the same in a to $\mathrm{c}$. Bar $=10 \mu \mathrm{m}$. b. Collagen I immunoreactivity in the BMZ (arrowhead). Both the epithelial and mesenchymal surfaces are irregular. The mean width of the BMZ was $4.4 \pm 0.5 \mu \mathrm{m}$. b, Perlecan immunoreactivity in the BMZ (arrowhead) and walls of blood vessels (arrows). The intensity was greater in the walls of blood vessels compared with the BMZ. The mean width of the BMZ was $4.3 \pm 0.4$ $\mu \mathrm{m}$. C, FGF-2 immunoreactivity was present in the BMZ (arrowhead), within and on the surface of basal cells (BC), and around and the walls of blood vessels (arrow). The mean width of the BMZ was $4.6 \pm 0.6 \mu \mathrm{m}$. 


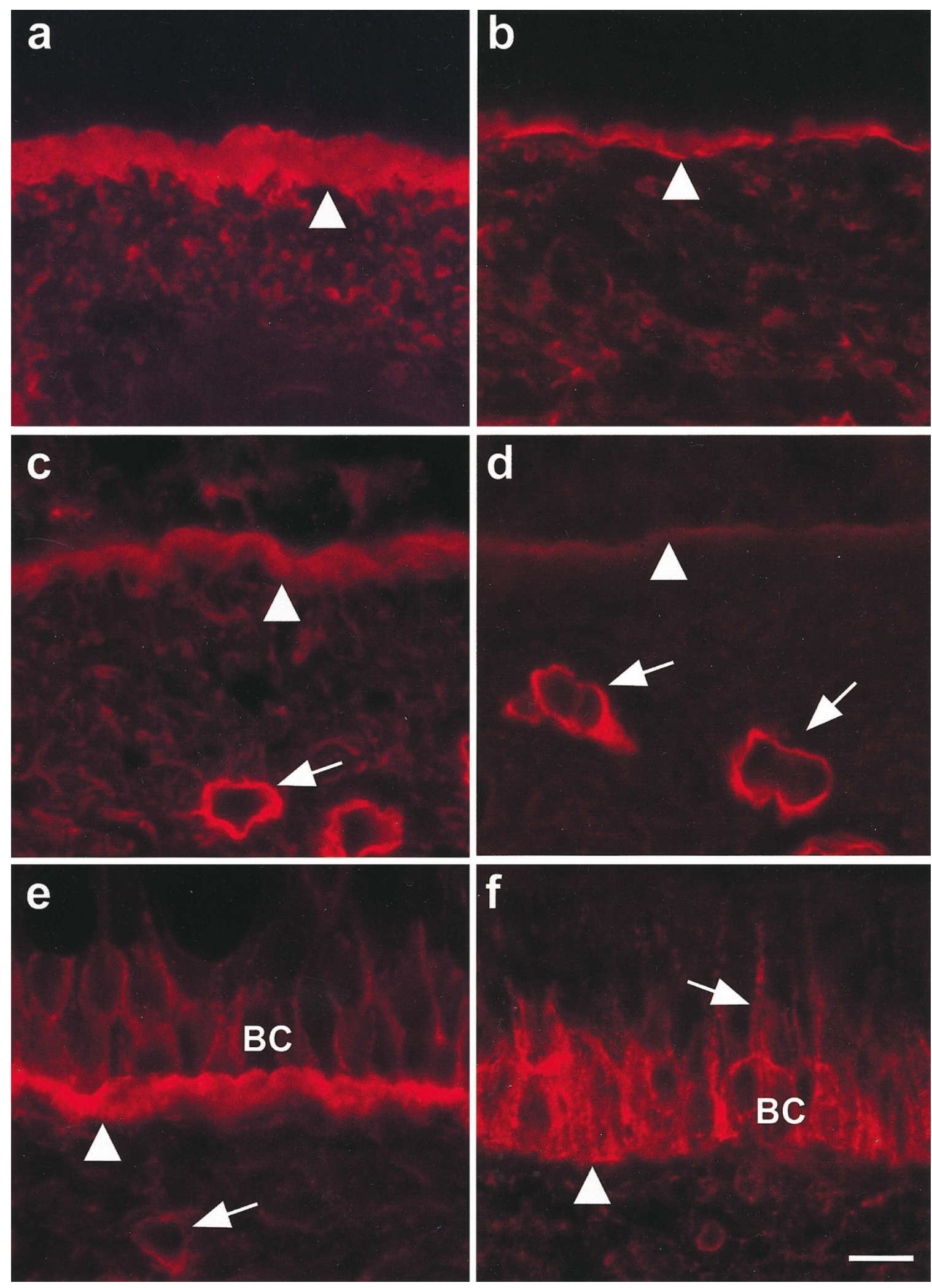

\section{Figure 3.}

a to $f$, From tracheal rings of HDMA-treated monkey. b, d, and f, From focal thin areas of the BMZ associated with leukocyte trafficking. a, c, and e, From areas without leukocyte. Bar $=10 \mu \mathrm{m}$. a, Collagen I immunoreactivity in the BMZ (arrowhead). Both the epithelial and mesenchymal surfaces are irregular. The mean width of the $\mathrm{BMZ}, 6.3 \pm 0.8 \mu \mathrm{m}$, was significantly greater $(p<0.05)$ than the filtered-air group. $\mathrm{b}$, Collagen I immunoreactivity was much less in the thin regions of the BMZ associated with leukocyte trafficking (arrowhead). c, Perlecan immunoreactivity in the BMZ (arrowhead) and walls of blood vessels (arrow). The intensity was greater in the walls of blood vessels compared with the BMZ. The mean width of the BMZ, $5.5 \pm 1.0 \mu \mathrm{m}$, was significantly greater $(p<0.05)$ than the filtered-air group. $\mathrm{d}$, Perleclan immunoreactivity was much less in the BMZ associated with leukocyte trafficking (arrowhead); however, the intensity was normal in the walls 


\section{Results}

\section{Morphology}

The tracheal rings used in this study were similar in both groups (Fig. 1a). The mean diameter of the trachea was $3.6 \pm 0.3 \mathrm{~mm}$ in the filtered-air group and $3.7 \pm 0.2 \mathrm{~mm}$ in the HDMA group. The mean height of the columnar epithelium in the filtered-air group was $49.3 \pm 5.2 \mu \mathrm{m}$ and in the HDMA group $47.3 \pm 2.6 \mu \mathrm{m}$. In each group, the epithelium was morphologically similar. The columnar epithelium was comprised mainly of ciliated and goblet cells; however, there appeared to be more goblet cells in the HDMA group. The basal cells formed a layer covering most of the $B M Z$. The $B M Z$ was a distinctive and wide structure that appeared to be wider in the HDMA group (Fig. 1b). The attenuated fibroblast sheath surrounding the $\mathrm{BMZ}$ was present in both groups. Leukocyte trafficking was present in focal areas of BMZ in the HDMA group (Fig. 1c). Fig. 1, b and $c$ are from the same area of the tracheal ring depicted in Figure 1a (areas 1 and 2, respectfully), illustrating the focal nature of leukocyte trafficking in the airway.

\section{Immunohistochemistry}

Collagen. In the BMZ of both the filtered-air and HDMA groups, immunoreactivity was strong for collagens I, III, and V. There was no apparent difference between the immunohistochemistry images of the three collagens, and collagen I was chosen for illustration (Figs. 2a and 3a). The mean width of the collagen I, III, and $\mathrm{V} B M Z$ in the filtered-air group was $4.4 \pm 0.5 \mu \mathrm{m}$, $4.5 \pm 0.3 \mu \mathrm{m}$, and $4.8 \pm 0.6 \mu \mathrm{m}$, respectively. In the HDMA group, immunoreactivity for collagens I, III, and V increased significantly in width $(p<0.05)$ to $6.3 \pm 0.8$ $\mu \mathrm{m}, 6.6 \pm 1.4 \mu \mathrm{m}$, and $5.7 \pm 0.6 \mu \mathrm{m}$, respectfully (Table 1). The significant increase in collagen $B M Z$ width in the HDMA group is characteristic BMZ remodeling. ANOVA indicated there were no differences between measurements of the collagen I, III, and V widths within treatment groups, illustrating the fact that they form heterogeneous fibers in the BMZ.

Perlecan. Immunoreactivity was localized in the $\mathrm{BMZ}$ of the epithelium and the walls of blood vessels in both the filtered-air and HDMA groups (Figs. 2b and 3c). The intensity was stronger in the walls of blood vessels compared with the $\mathrm{BMZ}$. The mean width of the perlecan $B M Z$ in the filtered-air group was $4.3 \pm$ $0.4 \mu \mathrm{m}$. The mean width of the perlecan $\mathrm{BMZ}$ in the HDMA group increased significantly $(p<0.05)$ to 5.5 $\pm 1.0 \mu \mathrm{m}$ (Table 1). Weak immunoreactivity was also seen in basal cells of the HDMA group. ANOVA indicated there were no differences between mea-
Table 1. Changes in Basement Membrane Zone Width during Postnatal Development of Rhesus Monkeys Exposed to HDMA

\begin{tabular}{lcc}
\hline & Filtered Air & HDMA \\
\hline Collagen I $(\mu \mathrm{m})$ & $4.4 \pm 0.5$ & $6.3 \pm 0.8^{a}$ \\
Collagen III $(\mu \mathrm{m})$ & $4.5 \pm 0.3$ & $6.6 \pm 1.4^{a}$ \\
Collagen V $(\mu \mathrm{m})$ & $4.8 \pm 0.6$ & $5.7 \pm 0.6^{a}$ \\
Perlecan $(\mu \mathrm{m})$ & $4.3 \pm 0.4$ & $5.5 \pm 1.0^{a}$ \\
FGF-2 $(\mu \mathrm{m})$ & $4.6 \pm 0.6$ & $6.2 \pm 0.8^{a}$ \\
\hline
\end{tabular}

Values are means \pm SD.

${ }^{a} p<0.05$ when compared with the filtered air groups.

surements of perlecan widths and collagen I, III, and V widths within treatment groups, demonstrating that perlecan is an integral constituent of the BMZ.

FGF-2. Immunoreactivity for FGF-2 in the BMZ mirrored that of perlecan in both treatment groups. FGF-2 immunoreactivity was localized in the BMZ of epithelium and the walls of blood vessels (Figs. $2 c$ and $3 e$ ). The intensity was less in blood vessels when compared with the BMZ. The FGF-2 immunoreactivity was distributed throughout the $\mathrm{BMZ}$, but the intensity was stronger on the epithelial surface. Immunoreactivity for FGF-2 was also present in and around basal cells. In the HDMA group, FGF-2 immunoreactivity within and around basal cells was much stronger than the filtered-air group. The FGF-2 immunoreactivity was weak in other extracellular matrix (ECM) sites. Overall, FGF-2 immunoreactivity was clearly more intense and more widely distributed in the HDMA group than in the filtered-air group. The mean width of the FGF-2 BMZ in the filtered-air group was 4.6 $\pm 0.6 \mu \mathrm{m}$. The mean width of the FGF-2 BMZ in the HDMA group increased significantly $(p<0.05)$ to $6.2 \pm$ $0.8 \mu \mathrm{m}$ (Table 1). Increased FGF-2 immunoreactivity in basal cells has been related to growth of the $B M Z$, suggesting the BMZ in the HDMA group was growing. The FGF-2 is stored in the BMZ through binding with perlecan. ANOVA indicated there were no differences between measurements of perlecan and FGF-2 widths within treatment groups, demonstrating that FGF-2 is stored throughout the BMZ. However, the FGF-2 immunoreactivity was stronger near the epithelial surface, indicating there may be concentration differences of FGF-2 within the BMZ. The FGF-2 BMZ increased significantly in width, suggesting that a consequence of remodeling is the capacity to store more FGF-2.

Leukocyte Trafficking in the BMZ. In focal areas of $B M Z$ in the HDMA group, leukocyte trafficking was present (Fig. 1c). The BMZ was thin in these areas, and both collagen and perlecan immunoreactivity were weak (Figs. 3b and d). The FGF-2 immunoreactivity was either absent or localized to the epithelial

Figure 3. (continued)

of blood vessels (arrows). e, There was more FGF-2 immunoreactivity in the BMZ from the HDMA group than the filtered-air group due to its greater width (arrowhead). The immunoreactivity associated with basal cells $(B C)$ was also greater in the HDMA group. The intensity was less in the walls of blood vessels compared with the BMZ (arrow). The width of the HDMA group, $6.2 \pm 0.8 \mu \mathrm{m}$, was significantly greater $(p<0.05)$ than the filtered-air group. $\mathrm{f}$, FGF-2 immunoreactivity is weak or absent in regions of the BMZ associated with leukocyte trafficking (arrowhead). However, strong FGF-2 immunoreactivity was associated with basal cells (BC) and the lateral intercellular space between columnar cells (arrow). e, From the same region of the tracheal ring as Figure $1 \mathrm{~b}$. $\mathrm{f}$, From the same region as Figure $1 \mathrm{c}$, illustrating the focal nature of the changes we observed in FGF-2 distribution around the tracheal ring. 
surface of the BMZ. However, there was very intense immunoreactivity for FGF-2 within and around the adjacent basal cells (Fig. 3f). The FGF-2 immunoreactivity associated with basal cells was on the cell surface, in the cytoplasm, and occasionally in the nucleus. There was also immunoreactivity for FGF-2 in the lateral intercellular space between columnar cells and in the ECM. Figure $3 e$ is from the same region of the tracheal ring as Figure $1 b$, and Figure $3 f$ from the same region as Figure 1c, illustrating the focal nature of the changes we observed in FGF-2 distribution in the tracheal ring.

\section{Discussion}

Remodeling of the $\mathrm{BMZ}$ involves increased deposition of collagens I, III, and V, resulting in thickening of the BMZ (Bousquet et al, 2000; Roche, 1997). Also associated with $B M Z$ thickening is the presence of tenacin and fibronectin (Chakir et al, 1996; Laitinen et al, 1997). A number of growth factors are known to be important in airway remodeling, eg, FGF-2, epidermal growth factor, endothelin-1, insulin-like growth factor, and transforming growth factor-beta (Holgate et al, 2000). Several of these growth factors have binding sites in the BMZ; however, only FGF-2 is stored in the $\mathrm{BMZ}$ (lozzo, 1998). In this study, we focused on FGF-2 in the developing tracheal BMZ in HDMA-sensitized infant rhesus monkeys, challenged with HDMA during the first postnatal 6 months. From our previous study, we know this is a time when the BMZ is undergoing active postnatal growth and FGF-2 plays a part in its development (Evans et al, 2002). We found that the collagen $\mathrm{BMZ}$ increased significantly in width in the HDMA group, indicating that remodeling had occurred. In the HDMA group, there was increased expression of FGF-2 in the remodeled $\mathrm{BMZ}$ and adjacent basal cells. In the developing airway, increased expression of FGF-2 in basal cells is related to growth of the BMZ (Evans et al, 2002), suggesting that remodeling of the BMZ was still occurring in the HDMA group.

The significance of remodeling on functions of the $B M Z$ is not known. A consequence of the increase in $\mathrm{BMZ}$ width is the potential to store an increased volume of FGF-2, suggesting that a larger pool of FGF-2 may exist in the tracheal $\mathrm{BMZ}$ of infant rhesus monkeys exposed to HDMA than in the filtered-air group. Such a pool of FGF-2 would be quickly available in response to stresses placed on the lung. This scenario is supported by the findings that baseline levels of FGF-2 are higher in bronchoalveolar lavage (BAL) from asthmatics than controls (Redington et al, 2001). At 10 minutes after segmental bronchoprovocation, there was a 5-fold increase in FGF-2 levels in BAL fluid recovered from allergenchallenged sites compared with saline-challenged sites in asthmatics. Similar findings have been shown following oxygen-induced pulmonary injury (Buch et al, 1995; Powers et al, 1994), demonstrating rapid release of FGF-2 from the BMZ.

In the HDMA group, many regions of the $\mathrm{BMZ}$ were associated with leukocyte trafficking. An influx of immune cells and eosinophils into the airway lumen is a characteristic of HDMA exposure to rhesus monkeys (Schelegle et al, 2001). One way leukocytes may enter the airway lumen is through pores in the BMZ (Evans et al, 2000b; Howat et al, 2001). Another is degradation of the BMZ by proteases. Degradation of the BMZ in the airways of asthmatics has been reported, and the matrix metalloproteinase MMP-3 has been implicated in this process (Dahlen et al, 1999). In the present study, expression of collagen, perlecan, and FGF-2 immunoreactivity in the BMZ was greatly reduced in the areas of leukocyte trafficking, suggesting it had been degraded by proteases released by leukocytes. Because most aeroallergens are also potent proteinases, it is possible that repeated exposure to aerosols of HDMA could also cause focal proteolytic damage to the $B M Z$ as well as stimulating an immune reaction (Robinson et al, 2001; Wan et al, 2001).

In these areas of leukocyte trafficking, there was strong expression of FGF-2 immunoreactivity in and around the adjacent basal cells. Fibroblast growth factor FGFR-1 is a receptor for FGF-2. In the airways, only the basal cells express FGFR-1 (Evans et al, 2002; Hughes and Hall, 1993). The FGF-2 released from the BMZ can be bound to the FGFR-1 on the surface of basal cells and initiate signaling pathways. This observation suggests that FGF-2 had been released from the $\mathrm{BMZ}$ and had relocated to the basal cell layer of the epithelium. Presumably, the basal cell-associated FGF-2 in these areas is being synthesized and utilized in an autocrine or paracrine manner by the basal cells.

There appears to be a significant relationship between basal cells, the BMZ, and FGF-2. Basal cells in the skin (Friedl et al, 1997; Hughes and Hall, 1993) and prostrate (Wang et al, 2000) as well as the developing airway (Evans et al, 2002) express FGF-2. Basal cells occupy a central position in the epithelial-mesenchymal trophic unit existing as a separate layer of cells covering most of the basement membrane. In this central position, they can interact with columnar epithelium, neurons, the basement membrane, and underlying mesenchymal cells. In addition, they interact with trafficking immune cells, neutrophils, and eosinophils. These interactions take place in the lateral intercellular space between basal and columnar cells. Basal cells express various molecules associated these processes such as neutral endopeptidase, CD44 adhesion molecule, intercellular adhesion molecule-1, and immunoglobulin E receptor. They also express the cytokine receptors, epidermal growth receptor, and FGFR-1 (Evans et al, 2001). The FGF-2 is a ubiquitous multifunctional growth factor that has a variety of functions during development and in the adult. Presumably, FGF-2 signaling via basal cells is associated with growth, differentiation, and the response to leukocyte trafficking in the developing airway of infant rhesus monkeys.

This study shows that exposure to HDMA causes significant remodeling of the tracheal BMZ in infant rhesus monkeys similar to that found in adults (Schelegle et al, 2001). It also implicates leukocyte trafficking, basal cells, and FGF-2 in the process of remodeling. 


\section{Methods}

Twelve infant rhesus monkeys, 30 days old and weighing $562.0 \pm 76.2 \mathrm{~g}$, were selected for these studies from California Regional Primate Research Center colony-born rhesus macaques (Macaca mulatta). Care and housing of animals before, during, and after treatment complied with the provisions of the Institute of Laboratory Animal Resources and conforms to practices established by the American Association for Accreditation of Laboratory Animal Care.

Six monkeys were sensitized to HDMA (Dermatophagoides farinae) at age 14 and 28 days by subcutaneous inoculation of $12.5 \mu \mathrm{g}$ HDMA in $10 \mathrm{mg}$ alum and intraperitoneal injection of $2.5 \times 10^{11}$ heat-killed Bordetella pertussis cells. Sensitized monkeys were exposed to 11 episodes of HDMA aerosol for 2 hours/day (435 $\pm 96 \mu \mathrm{g} / \mathrm{m}^{3}$ protein) for 5 days followed by 9 days of filtered air in order to simulate episodic exposure in humans. The HDMA sensitization was confirmed via skin testing with subcutaneous HDMA on day 38 of the exposure protocol. The six nonsensitized monkeys were exposed to filtered air (Schelegle et al, 2001).

Following the exposure protocol, monkeys were euthanized with an overdose of pentobarbital after being sedated with Telazol ( $8 \mathrm{mg} / \mathrm{kg} \mathrm{im})$ and anesthetized with Diprivan (0.1-0.2 $\mathrm{mg} / \mathrm{kg} / \mathrm{min}$, iv). The weight of the filtered-air group was $1513 \pm 137.2 \mathrm{~g}$ and the HDMA group $1522.0 \pm 167.9 \mathrm{~g}$. Monkeys were then necropsied following exsanguination through the abdominal aorta and the lungs prepared for analysis as previously described (Schelegle et al, 2001). Tracheal samples were sliced perpendicular to the long axis of the airway into rings. Tracheal rings were fixed in 1.0\% paraformaldehyde for 1 hour and embedded in paraffin.

For histology, 5- $\mu \mathrm{m}$ sections of tracheal rings were stained with hematoxylin and eosin. For immunohistochemistry, 5- $\mu \mathrm{m}$ sections of tracheal rings were deparaffinized in xylene, hydrated in ethanol, and washed in PBS. For collagen, sections were treated with pepsin (1.0 $\mathrm{mg}$ pepsin $/ \mathrm{ml} 3.0 \%$ acetic acid) at $37^{\circ} \mathrm{C}$ for 2 hours and blocked with bovine serum albumin, treated with antibody to collagen I (1:250), or collagen V (1:500) (rabbit, anti-human polyclonal antibody; Biogensis, Kingston, New Hampshire) or collagen III $(1: 10,000)$ (mouse, anti-human monoclonal antibody; BioGenex, San Ramon, California) overnight at $4^{\circ} \mathrm{C}$. For perlecan, sections were treated with $0.1 \%$ pronase in PBS for 30 minutes, rinsed in nanopure water followed by PBS, blocked with bovine serum albumin for 30 minutes, and incubated with an antibody to perlecan (1:2000; mouse, anti-human monoclonal antibody, clone 7B5; Zymed, San Francisco, California) overnight at $4^{\circ} \mathrm{C}$. For FGF-2, the sections were treated with $0.1 \% \mathrm{H}_{2} \mathrm{O}_{2}$ in methanol for 60 minutes followed by $50 \mathrm{mg} / \mathrm{ml}$ bovine testicular hyaluronidase in $0.05 \mathrm{M}$ Tris buffer ( $\mathrm{pH} 7.6$ ) for 30 minutes, blocked with $5.0 \%$ horse serum for 30 minutes, and incubated with an antibody to FGF-2 (1:750; mouse, anti-human monoclonal antibody, clone bFM-2; Upstate Technology, Lake Placid, New York) overnight at $4^{\circ} \mathrm{C}$. As a control, the primary antibody was replaced with PBS. Following immunohistochemistry, the sections were washed in PBS, treated with the secondary antibody (1:1000; Alexa Fluor 568; Molecular Probes, Inc, Eugene, Oregon) for 30 minutes, washed in PBS, and the coverslip mounted in ELF fluorescent safe media (Molecular Probes, Inc). The secondary antibody was replaced with PBS as another control. Fluorescence was visualized on an Olympus $\mathrm{BH}-2$ fluorescent microscope. All controls were negative.

The width of the $\mathrm{BMZ}$ was measured morphometrically to quantitate the immunohistochemical results. In human biopsy samples, it was demonstrated that 31 to 45 measurements, at least $20 \mu \mathrm{m}$ apart and covering $1000 \mu \mathrm{m} \mathrm{BMZ}$, are necessary to give an accuracy of $\pm 15.0 \%$ (Sullivan et al, 1998). In this study, eight micrographs were taken equidistant apart around the circumference of the trachea. The width of the BMZ was measured at four points $50 \mu \mathrm{m}$ apart on each micrograph. A total of $1600 \mu \mathrm{m}$ of BMZ was sampled in each tracheal ring in this manner. The average width of the $\mathrm{BMZ}$ was determined from these measurements for each animal. The mean and standard deviation of $\mathrm{BMZ}$ width for each group of six animals was then determined. The differences between filtered-air and HDMA groups were compared using Students $t$ test with significance set at $p<0.05$. The differences within filtered-air and HDMA groups were compared with ANOVA using Fischer's least protected significant difference, with significance set at $p<0.05$.

\section{References}

Adachi EHI and Hayashi T (1997). Basement-membrane stromal relationships: Interactions between collagen fibrils and the lamina densa. Inter Rev Cytol 173:73-156.

Bikfalvi A, Klein S, Pintucci G, and Rifkin DB (1997). Biological roles of fibroblast growth factor-2. Endocr Rev 18:26-45.

Bousquet J, Jeffery PK, Busse WW, Johnson M, and Vignola AM (2000) Asthma. From bronchoconstriction to airways inflammation and remodeling. Am J Respir Crit Care Med 161:1720-1745.

Brewster CE, Howarth PH, Djukanovic R, Wilson J, Holgate ST, and Roche WR (1990). Myofibroblasts and subepithelial fibrosis in bronchial asthma. Am J Respir Cell Mol Biol 3:507-511.

Buch S, Han RN, Liu J, Moore A, Edelson JD, Freeman BA, Post M, and Tanswell AK (1995). Basic fibroblast growth factor and growth factor receptor gene expression in $85 \%$ $\mathrm{O}_{2}$-exposed rat lung. Am J Physiol 268:L455-L464.

Chakir J, Laviolette M, Boutet M, Laliberte R, Dube J, and Boulet LP (1996). Lower airways remodeling in nonasthmatic subjects with allergic rhinitis. Lab Invest 75:735-744.

Crouch EC, Martin GR, Brody JS, and Laurie GW (1997). Basement membranes. In: Crystal RG, West JB, Wiebel ER, and Barnes PJ, editors. Lung. Philadelphia: Lippincott Raven, 769791.

Dahlen B, Shute J, and Howarth P (1999). Immunohistochemical localisation of the matrix metalloproteinases MMP-3 and MMP-9 within the airways in asthma. Thorax 54:590-596. 
Dowd CJ, Cooney CL, and Nugent MA (1999). Heparan sulfate mediates bFGF transport through basement membrane by diffusion with rapid reversible binding. J Biol Chem 274:5236-5244.

Evans MJ, Fanucchi MV, Van Winkle LS, Baker GL, Murphy AE, Nushio SJ, Sannes PL, and Plopper CG (In press, 2002). Fibroblast growth factor-2 during postnatal development of the tracheal basement membrane zone. Am J Physiol; Lung Cell Mol Physiol.

Evans MJ, Guha SC, Cox RA, and Moller PC (1993). Attenuated fibroblast sheath around the basement membrane zone in the trachea. Am J Respir Cell Mol Biol 8:188-192.

Evans MJ, Van Winkle LS, Fanucchi MV, Fleschner C, Wong V, Hyde D, and Plopper CG (2000a). Focal changes in the tracheal basement membrane of house dust mite sensitized rhesus monkeys. Am J Respir Crit Care Med 161:A276.

Evans MJ, Van Winkle LS, Fanucchi MV, and Plopper CG (1999). The attenuated fibroblast sheath of the respiratory tract epithelial-mesenchymal trophic unit. Am J Respir Cell Mol Biol 21:655-657.

Evans MJ, Van Winkle LS, Fanucchi MV, and Plopper CG (2001). Cellular and molecular characteristics of basal cells in airway epithelium. Exp Lung Res 27:401-415.

Evans MJ, Van Winkle LS, Fanucchi MV, Toskala E, Luck EC, Sannes PL, and Plopper CG (2000b). Three-dimensional organization of the lamina reticularis in the rat tracheal basement membrane zone. Am J Respir Cell Mol Biol 22: 393-397.

Folkman J, Klagsbrun M, Sasse J, Wadzinski M, Ingber D, and Vlodavsky I (1988). A heparin-binding angiogenic protein-basic fibroblast growth factor-is stored within basement membrane. Am J Pathol 130:393-400.

Friedl A, Chang Z, Tierney A, and Rapraeger AC (1997). Differential binding of fibroblast growth factor-2 and -7 to basement membrane heparan sulfate: Comparison of normal and abnormal human tissues. Am J Pathol 150:1443-1455.

Holgate ST, Davies DE, Lackie PM, Wilson SJ, Puddicombe SM, and Lordan JL (2000). Epithelial-mesenchymal interactions in the pathogenesis of asthma. J Allergy Clin Immunol 105:193-204.

Howat WJ, Holmes JA, Holgate ST, and Lackie PM (2001). Basement membrane pores in human bronchial epithelium: A conduit for infiltrating cells? Am J Pathol 158:673-680.

Hughes SE and Hall PA (1993). Immunolocalization of fibroblast growth factor receptor 1 and its ligands in human tissues. Lab Invest 69:173-182.

lozzo RV (1998). Matrix proteoglycans: From molecular design to cellular function. Annu Rev Biochem 67:609-652.

Laitinen A, Altraja A, Kampe M, Linden M, Virtanen I, and Laitinen LA (1997). Tenascin is increased in airway basement membrane of asthmatics and decreased by an inhaled steroid. Am J Respir Crit Care Med 156:951-958.

Merker HJ (1994). Morphology of the basement membrane. Microsc Res Tech 28:95-124.

Milanese M, Crimi E, Scordamaglia A, Riccio A, Pellegrino R, Canonica GW, and Brusasco V (2001). On the functional consequences of bronchial basement membrane thickening. J Appl Physiol 91:1035-1040.

Nugent MA and lozzo RV (2000). Fibroblast growth factor-2. Int J Biochem Cell Biol 32:115-120.
Powell PP, Wang CC, Horinouchi H, Shepherd K, Jacobson M, Lipson M, and Jones R (1998). Differential expression of fibroblast growth factor receptors 1 to 4 and ligand genes in late fetal and early postnatal rat lung. Am J Respir Cell Mol Biol 19:563-572.

Powers MR, Planck SR, Berger J, Wall MA, and Rosenbaum JT (1994). Increased expression of basic fibroblast growth factor in hyperoxic-injured mouse lung. J Cell Biochem 56:536-543.

Redington AE (2000). Fibrosis and airway remodelling. Clin Exp Allergy 30(Suppl) 1:42-45.

Redington AE, Roche WR, Madden J, Frew AJ, Djukanovic R, Holgate ST, and Howarth PH (2001). Basic fibroblast growth factor in asthma: Measurement in bronchoalveolar lavage fluid basally and following allergen challenge. J Allergy Clin Immunol 107:384-387.

Roberts CR, Wright TN, and Hascall VC (1997). Proteoglycans. In: Crystal RG, West JB, Wiebel ER, and Barnes PJ, editors. Lung. Philadelphia: Lippincott Raven, 757-767.

Robinson C, Baker SF, and Garrod DR (2001). Peptidase allergens, occludin and claudins. Do their interactions facilitate the development of hypersensitivity reactions at mucosal surfaces? Clin Exp Allergy 31:186-192.

Roche WR (1997). Fibroblasts. In: Barns PJ, Grunstein MM, Leff AR, and Woolcock AJ, editors. Asthma. Philadelphia: Lippincott Raven, 943-946.

Sannes PL, Burch KK, and Khosla J (1992). Immunohistochemical localization of epidermal growth factor and acidic and basic fibroblast growth factors in postnatal developing and adult rat lungs. Am J Respir Cell Mol Biol 7:230-237.

Sannes PL, Burch KK, Khosla J, McCarthy KJ, and Couchman JR (1993). Immunohistochemical localization of chondroitin sulfate, chondroitin sulfate proteoglycan, heparan sulfate proteoglycan, entactin, and laminin in basement membranes of postnatal developing and adult rat lungs. Am J Respir Cell Mol Biol 8:245-251.

Sannes PL and Wang J (1997). Basement membranes and pulmonary development. Exp Lung Res 23:101-108.

Schelegle ES, Gershwin LJ, Miller LA, Fanucchi MV, Van Winkle LS, Gerriets JP, Walby WF, Omlor AM, Buckpitt AR, Tarkington BK, Wong VJ, Joad JP, Pinkerton KB, Wu R, Evans MJ, Hyde DM, and Plopper CG (2001). Allergic asthma induced in rhesus monkeys by house dust mite (Dermatophagoides farinae). Am J Pathol 158:333-341.

Sullivan P, Stephens D, Ansari T, Costello J, and Jeffery P (1998). Variation in the measurements of basement membrane thickness and inflammatory cell number in bronchial biopsies. Eur Respir J 12:811-815.

Taipale J and Keski-Oja J (1997). Growth factors in the extracellular matrix. FASEB J 11:51-59.

Wan H, Winton HL, Soeller C, Taylor GW, Gruenert DC, Thompson PJ, Cannell MB, Stewart GA, Garrod DR, and Robinson C (2001). The transmembrane protein occludin of epithelial tight junctions is a functional target for serine peptidases from faecal pellets of Dermatophagoides pteronyssinus. Clin Exp Allergy 31:279-294.

Wang Z, Ikeda K, Wada Y, Foster HE, Weiss RM, and Latifpour J (2000). Expression and localization of basic fibroblast growth factor in diabetic rat prostate. BJU Int 85:945-952. 